\title{
Brush Conformation of Polyethylene Glycol Determines the Stealth Effect of Nanocarriers in the Low Protein Adsorption Regime
}

\author{
Mengyi Li, Shuai Jiang,* Johanna Simon, David Paßlick, Marie-Luise Frey, Manfred Wagner, \\ Volker Mailänder, Daniel Crespy, and Katharina Landfester*
}

Cite This: Nano Lett. 2021, 21, 1591-1598

Read Online

ACCESS

Llll Metrics \& More

Article Recommendations

Supporting Information

ABSTRACT: For nanocarriers with low protein affinity, we show that the interaction of nanocarriers with cells is mainly affected by the density, the molecular weight, and the conformation of polyethylene glycol (PEG) chains bound to the nanocarrier surface. We achieve a reduction of nonspecific uptake of ovalbumin nanocarriers by dendritic cells using densely packed PEG chains with a "brush" conformation instead of the collapsed "mushroom" conformation. We also control to a minor extent the dysopsonin adsorption by tailoring the conformation of attached PEG on the Low protein adsorption 'Brush' conformation $\quad$ Reduced cell uptake nanocarriers. The brush conformation of PEG leads to a stealth behavior of the nanocarriers with inhibited uptake by phagocytic cells, which is a prerequisite for successful in vivo translation of nanomedicine to achieve long blood circulation and targeted delivery. We can clearly correlate the brush conformation of PEG with inhibited phagocytic uptake of the nanocarriers. This study shows that, in addition to the surface's chemistry, the conformation of polymers controls cellular interactions of the nanocarriers.

KEYWORDS: stealth effect, PEGylation, nanoparticle, PEG conformation, protein corona

$\mathrm{O}$ nce nanoparticles enter the bloodstream, the adsorption of blood proteins on their surfaces usually leads to the formation of a protein corona, which switches their synthetic identity toward a biological identity depicted by bounded proteins. Surface modifications with zwitterions, carbohydrate moieties, and antifouling polymers are typically used to reduce protein adsorption. Recently, increasing evidence has revealed that enriching the protein corona with dysopsonins as "stealth" proteins is crucial for constructing drug delivery nanocarriers with prolonged blood circulation. ${ }^{1-3}$ Clusterin is a dysopsonin protein, which promotes prolonged blood circulation of nanoparticles by inhibiting phagocytic ingestion. In recent studies, we have shown that modifying polymer nanoparticles with attached polyethylene glycol (PEG) ${ }^{1}$ and alternative hydrophilic polymers, e.g., poly(phosphoester) ${ }^{1,4}$ and polysaccharide, ${ }^{5}$ leads to the enrichment of clusterin in protein corona, which was proved to be responsible for the stealth effect of the nanoparticles. However, the conformation of the attached polymers, which directly depends on their length and density at the surface, has not been investigated regarding the regulation of dysopsonin adsorption and subsequent cell interaction. The cell interaction may change dramatically depending on the polymer conformation even with the same

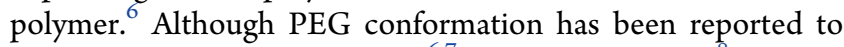
affect protein corona amount ${ }^{6,7}$ and composition, ${ }^{8}$ cellular uptake, ${ }^{9}$ or circulation of nanocarriers, ${ }^{7,8,10-12}$ there has been no clear correlation of PEG conformation with the abundance of specific dysopsonin proteins in the protein corona and resulting biological behavior of PEGylated nanocarriers in the low protein adsorption regime.

In this study, we demonstrate that, by tailoring a densely packed "brush" conformation of PEG on ovalbumin nanocarriers (OVA-NCs), we can considerably reduce the uptake in cells. Ovalbumin nanocapsules were chosen because of their good biodegradability and low protein adsorption. ${ }^{13,14}$ This low cell interaction is achieved by combining a brush conformation of PEG with low protein affinity of OVA-NCs, which minimizes the overall protein adsorption. OVA-NCs were covalently attached with PEG at varied lengths and densities, resulting in PEG chains with mushroom or brush conformation. The PEG conformation determines protein corona patterns and the abundance of distinct proteins in the corona. PEG chains with a brush conformation lead to increased adsorption of clusterin and decreased serum albumin in the corona. The PEG brush conformation at the low protein adsorbance regime with a clusterin-enriched surface leads to the stealth behavior of nanocarriers with inhibited phagocytic

Received: September 16, 2020

Revised: January 9, 2021

Published: February 9, 2021 


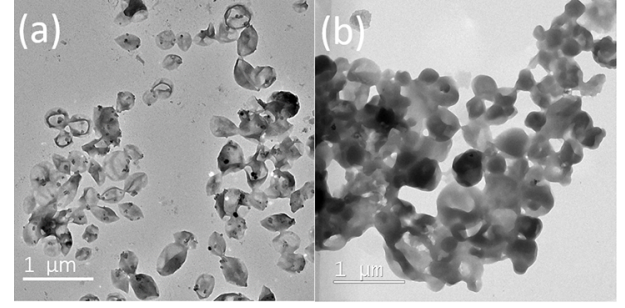

(c)

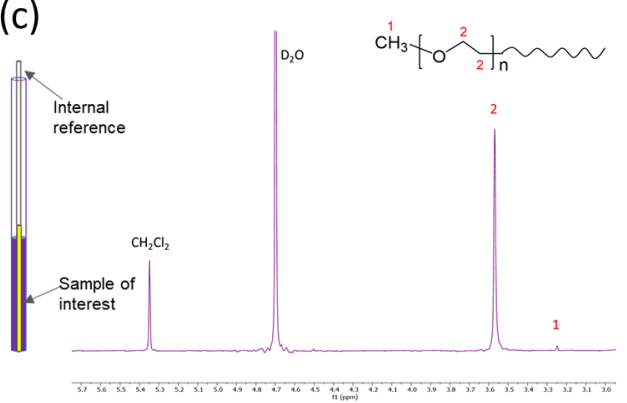

(d)

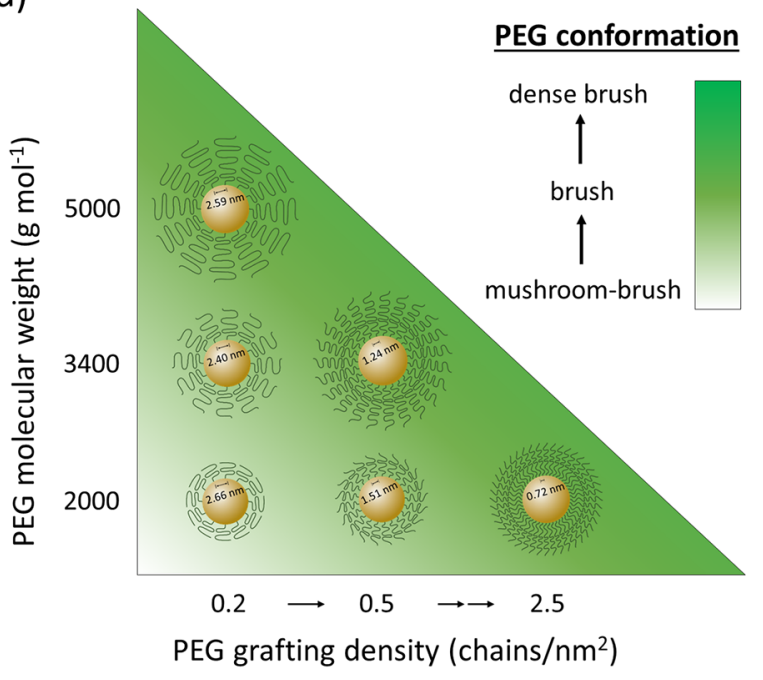

Figure 1. TEM images of (a) OVA-NCs and (b) OVA-PEG $2 \mathrm{k}_{2.5}$. (c) Schematic illustration of the quantification of PEG chains by ${ }^{1} \mathrm{H}$ NMR spectroscopy. (d) Correlation between molecular weight, grafting density, and the conformation of PEG chains on OVA-NCs.

Table 1. Comparison of the Flory Radius $\left(R_{\mathrm{F}}\right)$, Grafting Density, Distance between PEG Grafts $(D)$, and Length/Thickness of the PEG Layer $(L)^{a}$

\begin{tabular}{|c|c|c|c|c|c|c|}
\hline entry & PEG $M_{\mathrm{w}}\left[\mathrm{g} \mathrm{mol}^{-1}\right]$ & chains $\left[\mathrm{nm}^{-2}\right]$ & $R_{\mathrm{F}}[\mathrm{nm}]$ & $D[\mathrm{~nm}]$ & $L[\mathrm{~nm}]$ & PEG conformation \\
\hline OVA & & 0 & & & & \\
\hline OVA-PEG $2 \mathrm{k}_{0.2}$ & 2000 & 0.18 & 3.4 & 2.7 & 3.9 & mushroom-brush \\
\hline OVA-PEG2k 0.5 & 2000 & 0.54 & 3.4 & 1.5 & 5.7 & mushroom-brush \\
\hline OVA-PEG2k 2.5 & 2000 & 2.47 & 3.4 & 0.7 & 9.4 & dense brush \\
\hline OVA-PEG3.4k $\mathrm{k}_{0.2}$ & 3400 & 0.22 & 4.7 & 2.4 & 7.1 & brush \\
\hline OVA-PEG3.4k $\mathrm{k}_{0.8}$ & 3400 & 0.83 & 4.7 & 1.2 & 11.1 & dense brush \\
\hline OVA-PEG5k $\mathrm{k}_{0.2}$ & 5000 & 0.19 & 5.9 & 2.6 & 10.0 & brush \\
\hline
\end{tabular}

${ }^{a}$ These parameters were used to predict the PEG conformation according to the model of de Gennes. ${ }^{17}$ The interaction of PEG to nanocapsule surface cannot be quantified, and hence, it was not included in the calculation of the PEG conformation using the de Gennes model. We assume a homogeneous, not patchy, distribution of amino groups on the surface of OVA-NCs.

uptake. We establish a clear correlation of PEG conformation with quantitative analysis of adsorbed clusterin and stealth behavior of the resulting nanocarriers.

To precisely investigate the correlation between PEG conformation, protein corona composition, and cellular uptake, a well-defined system including defined nanocarriers and quantitative PEG modification is essential. We first synthesized OVA-NCs via a polyaddition reaction in a water-in-oil miniemulsion. Amino groups of ovalbumin were reacted with toluene diisocyanate, resulting in core-shell nanocapsules with a hydrodynamic diameter of ca. $250 \mathrm{~nm}$ (Figures 1a and S1). OVA-NCs were fluorescently labeled by encapsulating Cy5oligonucleotides for a cellular uptake study. OVA-NCs exhibited very low protein adsorption $\left(<0.5 \mathrm{mg} / \mathrm{m}^{2}\right)$ compared with reported nanoparticles, e.g., $\sim 7.7 \mathrm{mg} / \mathrm{m}^{2}$ for silica nanoparticles ${ }^{15}$ and $\sim 3.6 \mathrm{mg} / \mathrm{m}^{2}$ for polystyrene nanoparticles. ${ }^{1}$ Therefore, OVA-NCs serve as a suitable system for studying protein interaction with minimized nonspecific protein adsorption.

OVA-NCs were modified with PEG-isocyanate (MeO-PEGNCO, $M_{\mathrm{w}}=2000,3400$, or $5000 \mathrm{~g} \mathrm{~mol}^{-1}$ ) by reacting with the amino groups of OVA. The resulting NCs are denoted as OVA-PEG $2 \mathrm{k}_{n}$, OVA-PEG $3.4 \mathrm{k}_{n}$, and OVA-PEG5 $\mathrm{k}_{n}$, where $n$ is the grafting density of PEG (chains per $\mathrm{nm}^{2}$ ). The core-shell structure of the NCs was preserved after PEGylation (Figure 1b). PEG with a $M_{\mathrm{w}}$ larger than $2000 \mathrm{~g} \mathrm{~mol}^{-1}$ was reported to be necessary for an effective stealth effect. ${ }^{16}$ Indeed, grafted short PEG chains display a loss of flexibility. The grafting density of PEG was controlled by varying the PEG to NC stoichiometry. PEGylated NCs were repeatedly purified by centrifugation until no free polymers were detected in the supernatants (Figures S2 and S3). NCs before and after PEGylation were stable in water and blood plasma and displayed identical hydrodynamic diameters of ca. 250-300 $\mathrm{nm}$ (Table S1). The biodegradability of OVA-NCs was preserved after PEGylation (Figure S4).

The average number of PEG chains per $\mathrm{nm}^{2}$ surface was quantified by ${ }^{1} \mathrm{H}$ NMR spectroscopy (Figure 1c). The integration of resonance signals corresponding to ethylene glycol units (3.5-3.6 ppm) was compared with the signal of dichloromethane used as external standard (5.4-5.5 ppm) to quantify the number of ethylene glycol units (Figures 1c, S5, and S6). On the basis of PEG quantification and total surface area of the NCs, the number of PEG per $\mathrm{nm}^{2}$ was obtained (Table 1). The detailed calculation of PEG grafting density is described in Section 2.1 of the Supporting Information.

The stealth effect of the nanoparticles from PEGylation highly depends on the $M_{\mathrm{w}}$ and surface density of PEG, which leads to the transition of PEG conformation at the surface (Figure 1d). ${ }^{7,18-21}$ The conformation of surface-bound PEG was determined following de Gennes' model. ${ }^{17}$ The calculation is based on the Flory radius of PEG $\left(R_{\mathrm{F}}\right)$, distance between 
Table 2. $T_{1}$ Relaxation Time of Protons from $-\mathrm{CH}_{2}-\mathrm{CH}_{2}-$ Units in the PEG Main Chain and $-\mathrm{CH}_{3}$ End Groups for PEG2k and OVA-PEG Samples with Various Molecular Weights and Surface Grafting Densities ${ }^{a}$

\begin{tabular}{lccccc}
\multicolumn{1}{c}{ entry } & $\mathrm{T}_{1}\left(-\mathrm{CH}_{2}-\mathrm{CH}_{2}-\right)[\mathrm{s}]$ & $\mathrm{SD}\left(\times 10^{-3}\right)$ & $T_{1}\left(-\mathrm{CH}_{3}\right)[\mathrm{s}]$ & $\mathrm{SD}\left(\times 10^{-2}\right)$ & $\varphi\left(-\mathrm{CH}_{2} \mathrm{CH}_{2}-/-\mathrm{CH}_{3}\right)$ \\
PEG2k & 1.30 & 1.62 & 2.61 & 1.54 & 62 \\
OVA-PEG2k $\mathrm{k}_{0.2}$ & 1.41 & 1.24 & 3.91 & 1.31 & 91 \\
OVA-PEG2k $\mathrm{k}_{0.5}$ & 1.37 & 1.33 & 3.03 & 2.52 & 78 \\
OVA-PEG2k $\mathrm{k}_{2.5}$ & 1.33 & 1.79 & 2.82 & 1.82 & 43 \\
OVA-PEG3.4k $\mathrm{k}_{0.2}$ & 1.42 & 1.61 & 3.61 & 2.44 & 76 \\
OVA-PEG3.4k $\mathrm{k}_{0.8}$ & 1.34 & 1.17 & 3.42 & 1.29 & 65 \\
OVA-PEG5k 0.2 & 1.46 & 2.35 & 3.79 & 1.93 & 196
\end{tabular}

${ }^{a} \varphi$ represents the ratio of integrals of signals corresponding to $-\mathrm{CH}_{2}-\mathrm{CH}_{2}-$ and $-\mathrm{CH}_{3}$ end groups determined by ${ }^{1} \mathrm{H}$ NMR spectroscopy.

adjacent PEG chains $(D)$, and length/thickness of the grafted PEG layer $(L) .^{7}$ On the basis of these parameters, there are two main conformations that PEG can acquire: "mushroom" or "brush" (Table 1). ${ }^{17,22,23}$ At low grafting densities $\left(R_{\mathrm{F}} / D \leq\right.$ 1), PEG adopts a mushroom conformation. At increasing grafting densities $\left(R_{\mathrm{F}} / D>1\right)$, PEG chains experience a more extended "brush" conformation, eventually reaching a "dense brush" regime when the PEG layer thickness exceeds $R_{\mathrm{F}}$ by at least 2-fold $\left.\left(L / R_{\mathrm{F}}>2\right)\right)^{7,11,17,23}$ The detailed calculation of the PEG conformation regimes is described in Section 2.2 of the Supporting Information.

Following this model, an increasing grafting density from 0.2 to 2.5 chains $\mathrm{nm}^{-2}$ resulted in an intermediate (mushroombrush) conformation to a dense brush conformation for OVAPEG $2 \mathrm{k}_{n}$. For OVA-PEG3.4k $\mathrm{k}_{n}$, brush and dense brush conformations were obtained at a grafting density of 0.2 and 0.8 chains $\mathrm{nm}^{-2}$, respectively. In the case of OVA-PEG $5 \mathrm{k}_{n}$, a brush conformation was obtained even at a low density of 0.2 chains $\mathrm{nm}^{-2}$ due to the higher $M_{\mathrm{w}}$. Therefore, PEG length, density, and number of ethylene glycol units per $\mathrm{nm}^{2}$ can be precisely controlled so that each variable can be independently varied (Table 1 ). The correlation between $M_{\mathrm{w}} /$ grafting density and the conformation of grafted PEG is shown in Figure 1d.

The molecular conformation of grafted PEG chains was investigated by monitoring their ${ }^{1} \mathrm{H}$ NMR relaxation time, which yields information on the dynamics of macromolecular chains near a solid surface. ${ }^{24}$ At low grafting densities, polymer chains spread on the surface with a flat conformation where local motion of the segments is severely hindered. As grafting ratio increases, polymer chains repel each other and adopt a more extended "brush" configuration. An important observable for characterizing the dynamics of grafted polymer chains is the correlation time of local segmental motions. This parameter is evaluated from spin-lattice relaxation time $T_{1}$, which decreases with the increased mobility of the polymer chains. ${ }^{24} T_{1}$ relaxation times for $-\mathrm{CH}_{2}-\mathrm{CH}_{2}-$ repeating units and the terminating $-\mathrm{CH}_{3}$ group were first measured for nongrafted dissolved PEG2k and PEGylated NCs (Table 2). For PEG2k, the $T_{1}$ time for protons from $-\mathrm{CH}_{2}-\mathrm{CH}_{2}-$ decreased from 1.41 to $1.33 \mathrm{~s}$ as PEG density increased from 0.2 to 2.5 chains $\mathrm{nm}^{-2}$. The decrease of $T_{1}$ indicated an increased chain flexibility at higher grafting density, correlating with a brush conformation of stretched PEG chains. $\mathrm{T}_{1}$ for $-\mathrm{CH}_{2}-\mathrm{CH}_{2}-$ at PEG surface density of 2.5 chains $\mathrm{nm}^{-2}$ is close to the relaxation time of free PEG2k. The mobility of $-\mathrm{CH}_{2}-\mathrm{CH}_{2}-$ units of the free end is very different from the mobility of units attaching to the surface. Therefore, the $T_{1}$ relaxation time measured for $-\mathrm{CH}_{2}-\mathrm{CH}_{2}-$ represents an average value for the whole PEG chain. For the $-\mathrm{CH}_{3}$ group, $T_{1}$ decreased from 3.91 to $2.82 \mathrm{~s}$ as PEG density increased from 0.2 to 2.5 chains $\mathrm{nm}^{-2} . T_{1}$ for OVA-PEG $2 \mathrm{k}_{2.5}$ was close to the $T_{1}$ time $(2.61 \mathrm{~s})$ of the nonattached free PEG $2 \mathrm{k}$, indicating a high degree of mobility for the end group of stretched chains. This observation is in agreement with the model for PEG conformation, which predicted a morphology in the intermediate regime for OVA-PEG $2 \mathrm{k}_{0.2}$ and OVA-PEG $2 \mathrm{k}_{0.5}$ and a dense brush conformation for OVA-PEG $2 \mathrm{k}_{2.5}$ (Table 1). Similarly, OVA-PEG3.4k also showed a decreased $T_{1}$ time for $-\mathrm{CH}_{2}-\mathrm{CH}_{2}-$ and $-\mathrm{CH}_{3}$ protons as PEG density increased (Table 2).

To further confirm the PEG conformation, we calculated the ratio $(\varphi)$ of detected protons from the main chain to end groups by dividing the integral of protons from $-\mathrm{CH}_{2} \mathrm{CH}_{2}-$ (3.5-3.6 ppm) by the integral of terminal $-\mathrm{CH}_{3}$ groups (3.3 ppm) (Figure S6). For PEG2k, $\varphi$ decreased as PEG density increased (Table 2). This result shows that the increased fraction of protons from the $-\mathrm{CH}_{3}$ group can be detected by NMR compared with protons of $-\mathrm{CH}_{2}-\mathrm{CH}_{2}-$ in the main chain at increasing grafting density, which is due to the increased mobility of end groups of the extended polymer chains. At the highest grafting density of 2.5 chains $\mathrm{nm}^{-2}$, a $\varphi$ value of 43 was obtained, which is even lower than $\varphi$ for free PEG chains $(\varphi=62)$. This is due to a fraction of ethylene glycol units that are directly attached to the surface becoming less detectable by liquid-state ${ }^{1} \mathrm{H}$ NMR spectroscopy because of their lack of mobility. One should note that the $\varphi$ value of OVA-PEG2k samples with low grafting density is higher than the value for free PEG2k. This is because, at lower grafting densities, both $-\mathrm{CH}_{2} \mathrm{CH}_{2}-$ and terminal $-\mathrm{CH}_{3}$ groups interact with the surface due to the folding of flexible PEG chains. In each single chain, e.g., PEG $2 k$, there are 45 $-\mathrm{CH}_{2} \mathrm{CH}_{2}-$ units and $1-\mathrm{CH}_{3}$ group. The decrease of mobility for $-\mathrm{CH}_{3}$ is larger than the decrease of mobility of the $-\mathrm{CH}_{2} \mathrm{CH}_{2}-$ groups; therefore, the final $-\mathrm{CH}_{2} \mathrm{CH}_{2}-/-\mathrm{CH}_{3}$ ratio of the PEGs at low grafting density is higher than the free PEGs. This finding agrees well with a previous study, which simulated the correlation between PEG conformation and exposure of targeting ligands attaching to the end of the PEG chains. ${ }^{25}$ It was found when the conformation of the grafted chains was in the "mushroom" regime, the targeting moieties were more shielded within the tethered layers.

After defining the PEG conformations, we investigated the correlation between PEG conformation and protein corona and stealth effect of the nanocarriers. We performed three studies with well-defined systems displaying (i) increasing PEG density at constant $M_{\mathrm{w}}\left(2000 \mathrm{~g} \mathrm{~mol}^{-1}\right)$, (ii) increasing PEG $M_{\mathrm{w}}$ at constant grafting density (0.2 chains $\left.\mathrm{nm}^{-2}\right)$, and (iii) constant number of ethylene glycol units per $\mathrm{nm}^{2}$ while PEG conformation differed (mushroom-brush intermediate con- 
(a)

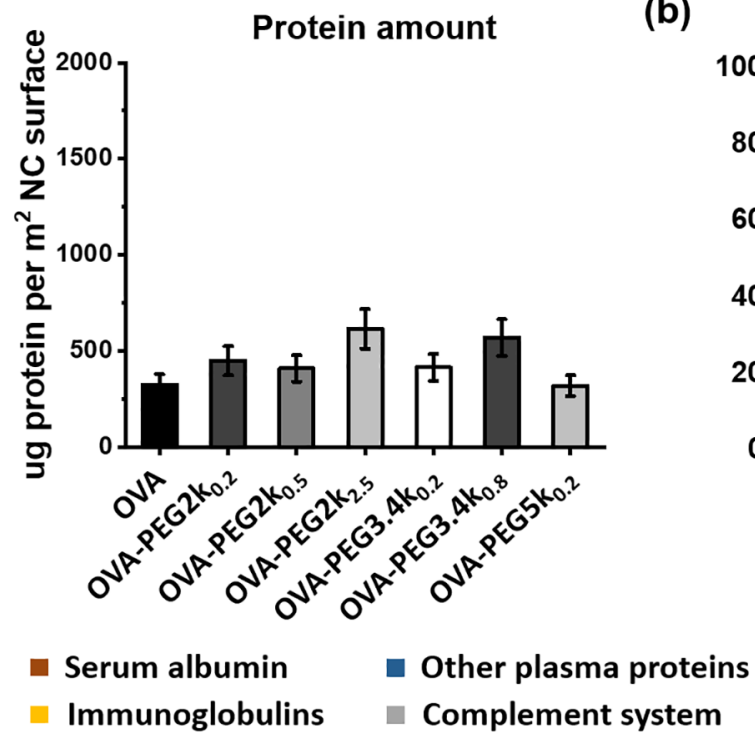

(b)

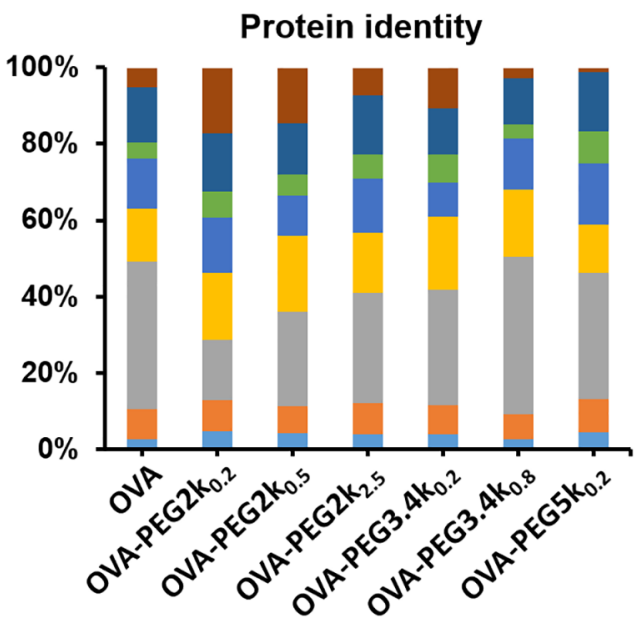

(c)

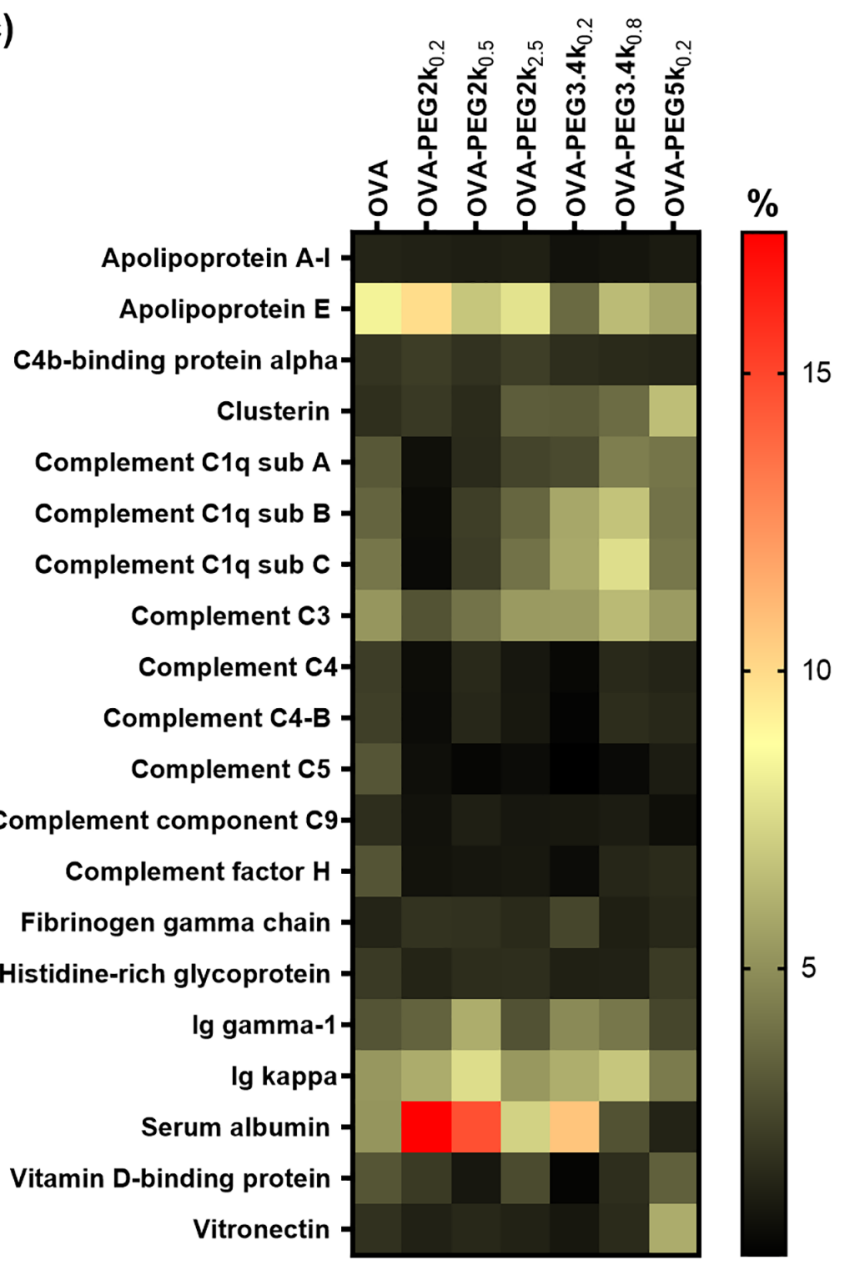

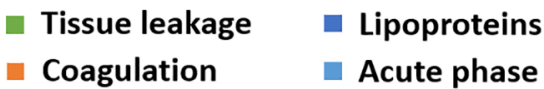

(d)

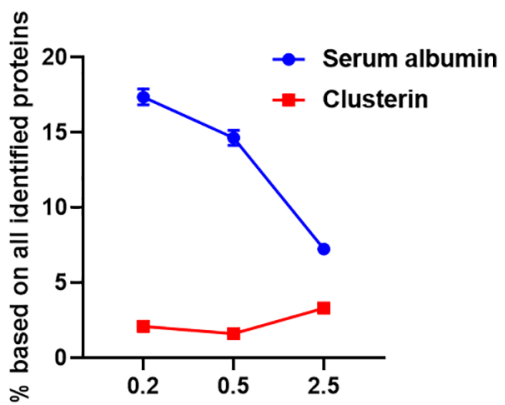

(e)

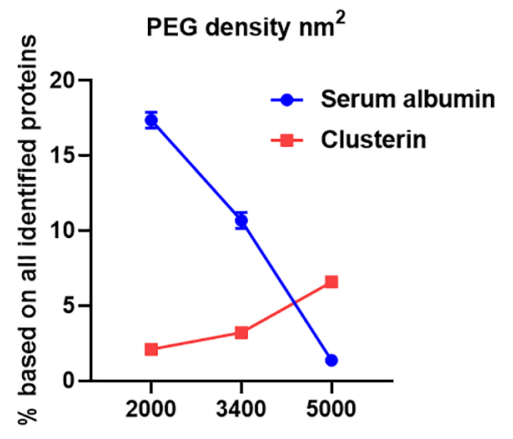

(f)

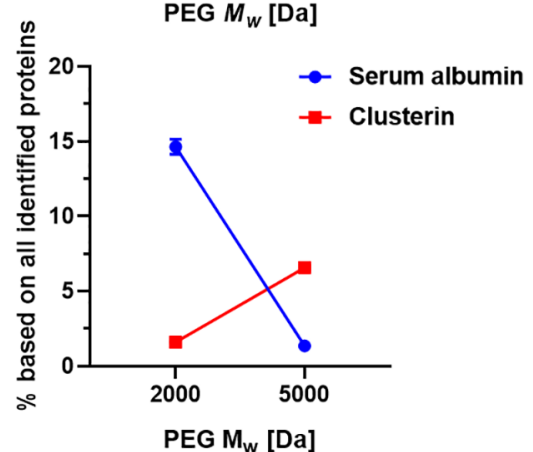

Figure 2. Quantitative proteomic analysis of the protein corona on OVA and OVA-PEG NCs. (a) Absolute amount of corona proteins ( $\mu$ g per $\mathrm{m}^{2}$ surface) determined by the Pierce assay $(n=3)$. (b) All corona proteins identified by quantitative LC-MS were classified into eight different groups according to their biological functions. (c) Heat map of the 20 most abundant proteins detected in the protein corona of OVA and OVA-PEG NCs determined by proteomic mass spectrometry. Only the proteins that constitute at least $1 \%$ of the protein corona on one of the nanocarriers are shown. (d-f) Relative amount (\%) of serum albumin and clusterin in the protein corona of OVA-PEG NCs: (d) increasing PEG density at a fixed molecular weight of $2000 \mathrm{~g} \mathrm{~mol}^{-1}$; (e) increasing molecular weight at a fixed grafting density of $0.2 \mathrm{chains} \mathrm{nm}^{-2}$; (f) constant number of ethylene glycol units per $\mathrm{nm}^{2}$ but with different PEG molecular weights and densities (mushroom-brush intermediate conformation: PEG2k at 0.5 chains/ $\mathrm{nm}^{2}$; brush conformation: PEG5k at 0.2 chains $/ \mathrm{nm}^{2}$ ). Values are expressed as the mean $\pm \mathrm{SD}$ of technical triplicates. 
(a) Constant: PEG $\boldsymbol{M}_{\mathrm{w}}$ 2k; Increase: PEG density

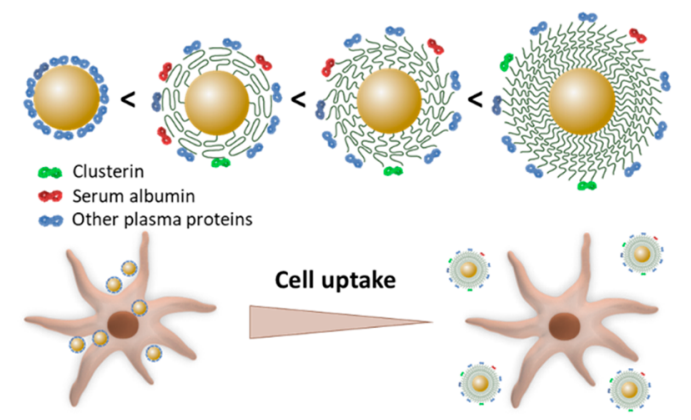

(c) Constant: PEG density $\left(0.2 / \mathrm{nm}^{2}\right)$; Increase: $M_{\mathrm{w}}$

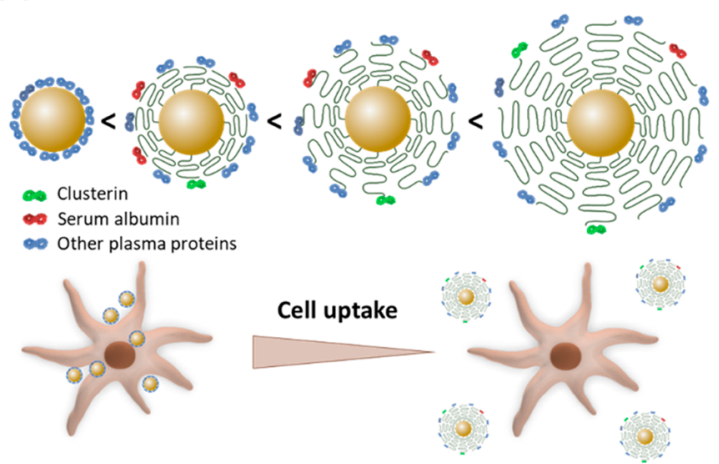

(e) Constant: $\mathrm{EG}$ unit $/ \mathrm{nm}^{2}$; Change: conformation

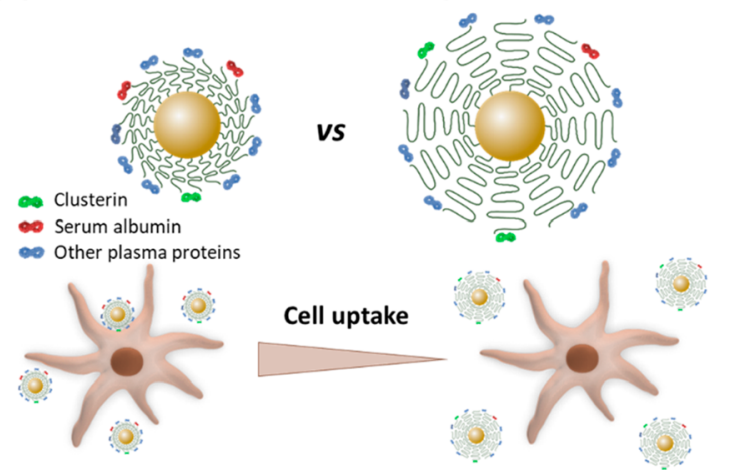

(b)

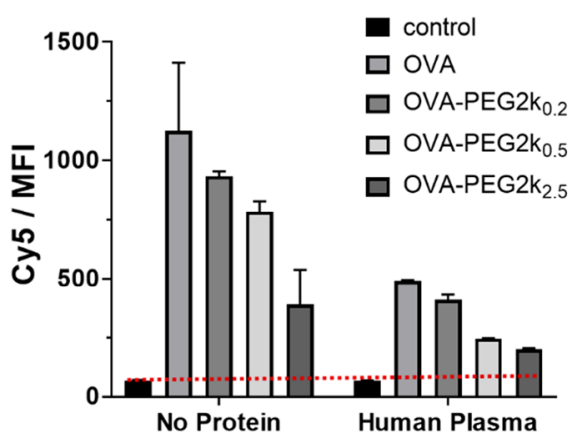

(d)

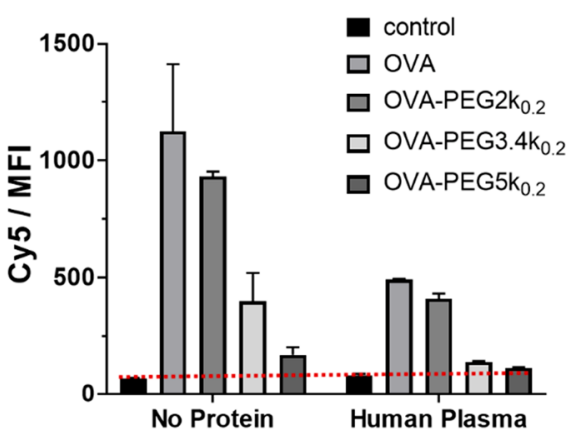

(f)

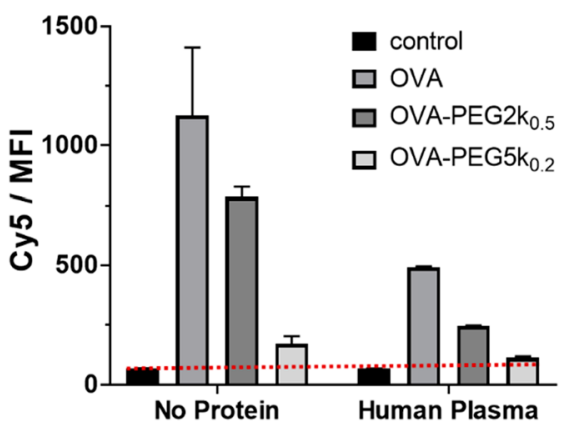

Figure 3. (a, c, e) Schematic illustration of the correlation between PEG conformation, clusterin density, and cellular uptake and (b, d, f) the cellular uptake results of OVA and OVA-PEG NCs by BMDCs at various PEG molecular weights and surface densities. (a, b) Increasing PEG density at constant molecular weight $\left(2000 \mathrm{~g} \mathrm{~mol}^{-1}\right)$. (c, d) Increasing molecular weight at constant grafting density $\left(0.2 \mathrm{chains} \mathrm{nm}^{-2}\right)$. (e, f) Constant number of ethylene glycol units per $\mathrm{nm}^{2}$ but with different PEG molecular weights and densities (mushroom-brush intermediate conformation: PEG2k at 0.5 chains $/ \mathrm{nm}^{2}$; brush conformation: PEG5k at 0.2 chains $\left./ \mathrm{nm}^{2}\right)$. BMDCs $\left(1 \times 10^{6}\right.$ cells $\left.\mathrm{mL}^{-1}\right)$ were incubated with various PEGylated OVA-NCs in the absence (no proteins) or presence of human plasma proteins (hP) for $4 \mathrm{~h}$. The median fluorescence intensity (MFI) was measured by flow cytometry. Cells treated with non-PEGylated OVA-NCs and untreated cells were used as controls.

formation: PEG5k at 0.2 chains $\mathrm{nm}^{-2}$; brush conformation: PEG2k at 0.5 chains $\mathrm{nm}^{-2}$ ).

To study the protein adsorption, OVA and OVA-PEG nanocarriers were incubated in human plasma at $37^{\circ} \mathrm{C}$ for $1 \mathrm{~h}$. All NCs remained stable in plasma, displaying constant sizes (Table S1). Corona proteins were detached from the NCs, and an absolute amount of adsorbed proteins was determined by the Pierce assay (Figure 2a). There was no significant difference of adsorbed protein amount between nonPEGylated and PEGylated NCs. The overall amount of corona proteins was $\sim 500 \mu \mathrm{g} \mathrm{m}^{-2}$, regardless of the chosen PEG derivative. Because the amount of adsorbed proteins on OVANCs is already very low, the PEG modification did not significantly decrease the adsorbed proteins. A similar phenomenon was observed for liposomes formulated from egg phosphatidyl choline and cholesterol in a previous report. ${ }^{26}$ The composition of protein corona was further analyzed by liquid chromatography-mass spectrometry (LCMS) to assess the biological identity of NCs covered with proteins. The identified proteins were categorized into eight different classes on the basis of their biological functions (Figure $2 \mathrm{~b}$ ). The protein corona of OVA-NCs was enriched with complement proteins, serum albumin, and immunoglobulins. A full list of all identified proteins and their amounts is provided as Supporting Information. 
To investigate the impact of PEG density and $M_{\mathrm{w}}$ on the interaction with blood proteins, the 20 most abundant corona proteins are shown in a heat map (Figure 2c). In contrast to non-PEGylated NCs, the protein corona of NCs coated with PEG at low density and low $M_{\mathrm{w}}$ was enriched with serum albumin and apolipoprotein E. For OVA-NCs with high PEG density and higher $M_{w}$, the protein corona was enriched with vitronectin and clusterin. In previous reports, ${ }^{1,4}$ it was found that clusterin specifically adsorbed on PEGylated polystyrene nanoparticles. In this study, we also showed that an increasing PEG density and chain length led to an enhanced adsorption of clusterin. Moreover, we found herein that serum albumin specifically interacts with non-PEGylated surfaces and binds significantly less to PEGylated NCs. One should note that serum albumin makes up to $60 \%$ of proteins in the serum. In contrast, clusterin is a low abundant protein and only makes up to $0.14 \%$ of all serum proteins. ${ }^{27}$

Therefore, we further investigated how PEG density and $M_{\mathrm{w}}$ influence the adsorption of clusterin and serum albumin on NCs. For NCs functionalized with PEG2k (Figure 2d), the amount of serum albumin decreased with increasing PEG density, whereas the amount of clusterin increased. The same trend was observed for the PEG $M_{\mathrm{w}}$ increasing from $2 \mathrm{k}$ to $5 \mathrm{k}$ at constant grafting density of $\sim 0.2$ chains $\mathrm{nm}^{-2}$ (Figure 2e). Indeed, the amount of serum albumin decreased from $17 \%$ to $1 \%$ with increasing $M_{w}$, whereas the amount of clusterin increased from $2 \%$ to $7 \%$. Furthermore, we compared the abundance of serum albumin and clusterin on OVA-NCs modified with the same number of ethylene glycol units per $\mathrm{nm}^{2}$ (Figure 2f) for which different PEG conformations were formed from varied $M_{\mathrm{w}}$ and density combinations. We found that brush conformation of PEG leads to the enrichment of clusterin and decreased concentration of serum albumin. Comparable trends were also obtained for human serum as the protein source (Figure S7). Moreover, we calculated the absolute amounts of serum albumin and clusterin on nanoparticles by combining the data from the Pierce assay with LC-MS data. As shown in Figure S8, the absolute amounts of serum albumin and clusterin show similar trends as shown in Figure $2 \mathrm{~d}-\mathrm{f}$. In brief, the protein corona study demonstrated that PEG conformation mediates a specific protein adsorption and shapes the protein corona profile.

The main feature of stealthy nanocarriers is their prolonged blood circulation, which is due to reduced unspecific cell interactions. To investigate stealth properties of PEG-modified OVA-NCs, we incubated OVA-NCs with bone marrowderived dendritic cells (BMDCs), which are phagocytic cells known to take up nanoparticles unspecifically. ${ }^{5}$

First, we investigated the effect of PEG density on the stealth behavior of OVA-NCs. The cellular uptake of OVA-NCs modified with PEG2k with various PEG conformations was measured by flow cytometry. All PEGylated NCs showed a reduced cellular uptake compared to non-PEGylated NCs. The effective internalization of OVA-NCs in dendritic cells was confirmed by using confocal laser scanning microscopy in our previous studies. ${ }^{14,28}$ The increased grafting density resulted in a reduced cellular uptake (Figure $3 \mathrm{a}, \mathrm{b}$ ). From the calculation in Table 1, the thickness of the PEG layer increased from 3.9 to $9.4 \mathrm{~nm}$ with an increasing density of PEG2k from 0.2 to 2.5 chains $\mathrm{nm}^{-2}$. The thicker and densely packed PEG layer was more effective for reducing NP interactions with the cell membrane. ${ }^{25}$ Remarkably, the cellular uptake was further reduced by the incubation with human plasma. The combination of dense brush conformation and protein corona enhanced the stealth effect of the nanocarriers (Figure 2d), which is expected to achieve prolonged blood circulation in vivo. $^{29}$

Second, we investigated the effect of PEG $M_{\mathrm{w}}$ on the stealth effect of OVA-NCs. For this aim, the PEG surface density was kept constant $\left(\sim 0.2\right.$ chains $\left.\mathrm{nm}^{-2}\right)$, while the $M_{\mathrm{w}}$ of PEG was varied. As shown in Figure 3c,d, the cellular uptake of the NCs decreased as the PEG $M_{\mathrm{w}}$ increased, which is well correlated with PEG conformation at the NCs' surface. The increase of PEG $M_{\mathrm{w}}$ from $2 \mathrm{k}$ to $5 \mathrm{k}$ resulted in a conformational transition from intermediate (mushroom-brush) to brush conformation. Densely packed PEG brushes have been reported to induce a reduction of cell adhesion on surfaces. ${ }^{30}$ This effect was not dependent on the addition or presence of proteins. Moreover, brush conformation of PEG led to a protein corona with slightly enriched adsorption of clusterin on the NC surface $(>3$ times increase, Figure 2e), which further reduced the cellular uptake to almost zero when the two effects (PEG conformation and clusterin) were combined (Figure 3d).

Third, we studied the stealth effect of OVA-NCs that have an equal number of ethylene glycol units on the surface but a varied conformation of PEG (Figure 3e). OVA-NCs were either modified with PEG2k at a surface density of 0.5 chains $\mathrm{nm}^{-2}$ or grafted with PEG5k at 0.2 chains $\mathrm{nm}^{-2}$. The binding assays revealed two distinct results (Figure $3 \mathrm{f}$ ). A significantly lower uptake was observed for PEG5k-modified NCs despite a lower PEG density. From the conformation study (Table 1), OVA-PEG5 $\mathrm{k}_{0.2}$ possesses a brush conformation of PEG, which results in a thicker hydration layer $(10.0 \mathrm{~nm})$ compared with an intermediate PEG conformation displayed in OVAPEG2 $\mathrm{k}_{0.5}$ NCs (coating thickness: $5.7 \mathrm{~nm}$ ). The incubation of NCs with human plasma resulted in a further decrease of cellular uptake. In particular, NCs PEGylated with a brush conformation showed very low cell binding, which is comparable to the control group without NC treatment. Similar trends were obtained with protein sources from mice and bovine (Figure S9).

The effects of PEG length and density on protein adsorption and/or macrophage uptake of the nanoparticles were intensively investigated. ${ }^{7,8,11,31,32}$ Overall, an increased surface density and length of PEG are beneficial for suppressing nonspecific protein adsorption and phagocytic uptake. However, varied thresholds regarding the $M_{\mathrm{w}}{ }^{31}$ and surface density $^{7,11}$ of the PEG were reported for achieving an effective inhibition of protein adsorption and/or cellular uptake, which can be attributed to different material properties of nanoparticles and PEG quantification methods. ${ }^{33}$ Walkey et al. ${ }^{32}$ found that, in addition to reduced macrophage uptake, an increase in the PEG density changes the composition of the adsorbed protein layer and decreases the total serum protein adsorption. The adsorption of smaller proteins is favored as the PEG density increases. Sacchetti et al. ${ }^{8}$ showed that a change of PEG conformation from the mushroom to mushroombrush transition state affected the relative abundance of the major constituents of the protein corona for the carbon nanotubes. Up to now, there has been no clear correlation of the abundance of dysopsonin proteins with PEG conformations and phagocytic uptake established.

In summary, we demonstrated that, for PEGylated nanocarriers in the low protein adsorption regime, the density and conformation of PEG mainly determine the interaction of the nanocarriers to cells. A brush conformation is superior to a 
mushroom conformation for achieving stealthy nanocarriers with low interactions to the cell. The conformation additionally allows the control of the specific adsorption of dysopsonin on the nanocarriers. This is the first study to correlate a welldefined polymer conformation with quantitative high-resolution protein corona analysis and the interaction with phagocytic cells. Our study shows that the conformation of attached polymers can regulate the adsorption of dysopsonin proteins and control the biological fate of nanocarriers. This is an important step toward understanding and controlling the stealth effect of nanocarriers.

\section{ASSOCIATED CONTENT}

\section{SI Supporting Information}

The Supporting Information is available free of charge at https://pubs.acs.org/doi/10.1021/acs.nanolett.0c03756.

Experimental section, calculation of surface density and conformation, and supplementary results (PDF)

\section{AUTHOR INFORMATION}

\section{Corresponding Authors}

Shuai Jiang - Max Planck Institute for Polymer Research, 55128 Mainz, Germany; 이이.org/0000-0002-86393495; Email: jiangs@mpip-mainz.mpg.de

Katharina Landfester - Max Planck Institute for Polymer Research, 55128 Mainz, Germany; 이이.org/0000-00019591-4638; Email: landfester@mpip-mainz.mpg.de

\section{Authors}

Mengyi Li - Max Planck Institute for Polymer Research, 55128 Mainz, Germany

Johanna Simon - Max Planck Institute for Polymer Research, 55128 Mainz, Germany; Department of Dermatology, Johannes-Gutenberg University, 55131 Mainz, Germany

David Paßlick - Max Planck Institute for Polymer Research, 55128 Mainz, Germany; Department of Dermatology, Johannes-Gutenberg University, 55131 Mainz, Germany

Marie-Luise Frey - Max Planck Institute for Polymer Research, 55128 Mainz, Germany

Manfred Wagner - Max Planck Institute for Polymer Research, 55128 Mainz, Germany

Volker Mailänder - Department of Dermatology, JohannesGutenberg University, 55131 Mainz, Germany; Max Planck Institute for Polymer Research, 55128 Mainz, Germany

Daniel Crespy - Department of Materials Science and Engineering, School of Molecular Science and Engineering, Vidyasirimedhi Institute of Science and Technology (VISTEC), Rayong 21210, Thailand

Complete contact information is available at: https://pubs.acs.org/10.1021/acs.nanolett.0c03756

\section{Notes}

The authors declare no competing financial interest.

\section{ACKNOWLEDGMENTS}

We acknowledge Stefan Schuhmacher for advice on the scheme design in Figures ${ }^{1} d$ and ${ }^{3}$ a,c,e.

\section{REFERENCES}

(1) Schöttler, S.; Becker, G.; Winzen, S.; Steinbach, T.; Mohr, K.; Landfester, K.; Mailänder, V.; Wurm, F. R. Protein adsorption is required for stealth effect of poly(ethylene glycol)- and poly- (phosphoester)-coated nanocarriers. Nat. Nanotechnol. 2016, 11, 372-377.

(2) Lu, X.; Xu, P.; Ding, H.-M.; Yu, Y.-S.; Huo, D.; Ma, Y.-Q. Tailoring the component of protein corona via simple chemistry. Nat. Commun. 2019, 10, 1-14.

(3) Takeuchi, T.; Kitayama, Y.; Sasao, R.; Yamada, T.; Toh, K.; Matsumoto, Y.; Kataoka, K. Molecularly imprinted nanogels acquire stealth in situ by cloaking themselves with native dysopsonic proteins. Angew. Chem. 2017, 129, 7194-7198.

(4) Simon, J.; Wolf, T.; Klein, K.; Landfester, K.; Mailänder, V.; Wurm, F. R. Hydrophilicity regulates the stealth properties of polyphosphoester-coated nanocarriers. Angew. Chem., Int. Ed. 2018, $57,5548-5553$.

(5) Kang, B.; Okwieka, P.; Schöttler, S.; Winzen, S.; Langhanki, J.; Mohr, K.; Opatz, T.; Mailänder, V.; Landfester, K.; Wurm, F. R. Carbohydrate-Based Nanocarriers Exhibiting Specific Cell Targeting with Minimum Influence from the Protein Corona. Angew. Chem., Int. Ed. 2015, 54, 7436-7440.

(6) Schroffenegger, M.; Leitner, N. S.; Morgese, G.; Ramakrishna, S. N.; Willinger, M.; Benetti, E. M.; Reimhult, E. Polymer Topology Determines the Formation of Protein Corona on Core-Shell Nanoparticles. ACS Nano 2020, 14, 12708.

(7) Perry, J. L.; Reuter, K. G.; Kai, M. P.; Herlihy, K. P.; Jones, S. W.; Luft, J. C.; Napier, M.; Bear, J. E.; DeSimone, J. M. PEGylated PRINT Nanoparticles: The Impact of PEG Density on Protein Binding, Macrophage Association, Biodistribution, and Pharmacokinetics. Nano Lett. 2012, 12, 5304-5310.

(8) Sacchetti, C.; Motamedchaboki, K.; Magrini, A.; Palmieri, G.; Mattei, M.; Bernardini, S.; Rosato, N.; Bottini, N.; Bottini, M. Surface Polyethylene Glycol Conformation Influences the Protein Corona of Polyethylene Glycol-Modified Single-Walled Carbon Nanotubes: Potential Implications on Biological Performance. ACS Nano 2013, 7, 1974-1989.

(9) Pelaz, B.; del Pino, P.; Maffre, P.; Hartmann, R.; Gallego, M.; Rivera-Fernandez, S.; de la Fuente, J. M.; Nienhaus, G. U.; Parak, W. J. Surface functionalization of nanoparticles with polyethylene glycol: effects on protein adsorption and cellular uptake. ACS Nano 2015, 9, 6996-7008

(10) Zhou, H.; Fan, Z.; Li, P. Y.; Deng, J.; Arhontoulis, D. C.; Li, C. Y.; Bowne, W. B.; Cheng, H. Dense and Dynamic Polyethylene Glycol Shells Cloak Nanoparticles from Uptake by Liver Endothelial Cells for Long Blood Circulation. ACS Nano 2018, 12, 10130-10141.

(11) Yang, Q.; Jones, S. W.; Parker, C. L.; Zamboni, W. C.; Bear, J. E.; Lai, S. K. Evading immune cell uptake and clearance requires PEG grafting at densities substantially exceeding the minimum for brush conformation. Mol. Pharmaceutics 2014, 11, 1250-1258.

(12) Bertrand, N.; Grenier, P.; Mahmoudi, M.; Lima, E. M.; Appel, E. A.; Dormont, F.; Lim, J.-M.; Karnik, R.; Langer, R.; Farokhzad, O. C. Mechanistic understanding of in vivo protein corona formation on polymeric nanoparticles and impact on pharmacokinetics. Nat. Commun. 2017, 8, 777.

(13) Jiang, S.; Xiao, M.; Sun, W.; Crespy, D.; Mailänder, V.; Peng, X.; Fan, J.; Landfester, K. Synergistic Anticancer Therapy by Ovalbumin Encapsulation-Enabled Tandem ROS Generation. Angew. Chem. 2020, 132, 20183-20191.

(14) Paßlick, D.; Piradashvili, K.; Bamberger, D.; Li, M.; Jiang, S.; Strand, D.; Wich, P. R.; Landfester, K.; Bros, M.; Grabbe, S.; Mailänder, V. Delivering all in one: Antigen-nanocapsule loaded with dual adjuvant yields superadditive effects by $\mathrm{DC}$-directed $\mathrm{T}$ cell stimulation. J. Controlled Release 2018, 289, 23-34.

(15) Jiang, S.; Prozeller, D.; Pereira, J.; Simon, J.; Han, S.; Wirsching, S.; Fichter, M.; Mottola, M.; Lieberwirth, I.; Morsbach, S.; et al. Controlling protein interactions in blood for effective liver immunosuppressive therapy by silica nanocapsules. Nanoscale 2020, 12, 2626-2637.

(16) Owens, D. E., III; Peppas, N. A. Opsonization, Biodistribution, and Pharmacokinetics of Polymeric Nanoparticles. Int. J. Pharm. 2006, 307, 93-102. 
(17) de Gennes, P. Conformations of Polymers Attached to an Interface. Macromolecules 1980, 13, 1069-1075.

(18) Gref, R.; Lück, M.; Quellec, P.; Marchand, M.; Dellacherie, E.; Harnisch, S.; Blunk, T.; Müller, R. 'Stealth'corona-core nanoparticles surface modified by polyethylene glycol (PEG): influences of the corona (PEG chain length and surface density) and of the core composition on phagocytic uptake and plasma protein adsorption. Colloids Surf., B 2000, 18, 301-313.

(19) Mosqueira, V. C. F.; Legrand, P.; Morgat, J.-L.; Vert, M.; Mysiakine, E.; Gref, R.; Devissaguet, J.-P.; Barratt, G. Biodistribution of long-circulating PEG-grafted nanocapsules in mice: effects of PEG chain length and density. Pharm. Res. 2001, 18, 1411-1419.

(20) Moghimi, S. M.; Szebeni, J. Stealth liposomes and long circulating nanoparticles: critical issues in pharmacokinetics, opsonization and protein-binding properties. Prog. Lipid Res. 2003, 42, 463478.

(21) Malmsten, M.; Emoto, K.; Van Alstine, J. M. Effect of chain density on inhibition of protein adsorption by poly (ethylene glycol) based coatings. J. Colloid Interface Sci. 1998, 202, 507-517.

(22) Storm, G.; Belliot, S. O.; Daemen, T.; Lasic, D. D. Surface modification of nanoparticles to oppose uptake by the mononuclear phagocyte system. Adv. Drug Delivery Rev. 1995, 17, 31-48.

(23) Damodaran, V. B.; Fee, C. J.; Ruckh, T.; Popat, K. C. Conformational studies of covalently grafted poly (ethylene glycol) on modified solid matrices using X-ray photoelectron spectroscopy. Langmuir 2010, 26, 7299-7306.

(24) Tajouri, T. Nuclear Magnetic Resonance Spectroscopy of Polymers at Surfaces. Trends Appl. Spectrosc. 2013, 10, 93-120.

(25) Li, Y.; Kröger, M.; Liu, W. K. Endocytosis of PEGylated Nanoparticles Accompanied by Structural and Free Energy Changes of the Grafted Polyethylene Glycol. Biomaterials 2014, 35, 84678478.

(26) Weber, C.; Voigt, M.; Simon, J.; Danner, A.-K.; Frey, H.; Mailänder, V.; Helm, M.; Morsbach, S.; Landfester, K. Functionalization of liposomes with hydrophilic polymers results in macrophage uptake independent of the protein corona. Biomacromolecules 2019, 20, 2989-2999.

(27) Schöttler, S.; Klein, K.; Landfester, K.; Mailänder, V. Protein source and choice of anticoagulant decisively affect nanoparticle protein corona and cellular uptake. Nanoscale 2016, 8, 5526-5536.

(28) Piradashvili, K.; Fichter, M.; Mohr, K.; Gehring, S.; Wurm, F. R.; Landfester, K. Biodegradable Protein Nanocontainers. Biomacromolecules 2015, 16, 815-821.

(29) Kang, B.; Okwieka, P.; Schöttler, S.; Seifert, O.; Kontermann, R. E.; Pfizenmaier, K.; Musyanovych, A.; Meyer, R.; Diken, M.; Sahin, U.; Mailänder, V.; Wurm, F. R.; Landfester, K. Tailoring the stealth properties of biocompatible polysaccharide nanocontainers. Biomaterials 2015, 49, 125-134.

(30) Du, H.; Chandaroy, P.; Hui, S. W. Grafted poly-(ethylene glycol) on lipid surfaces inhibits protein adsorption and cell adhesion. Biochim. Biophys. Acta, Biomembr. 1997, 1326, 236-248.

(31) He, Q.; Zhang, J.; Shi, J.; Zhu, Z.; Zhang, L.; Bu, W.; Guo, L.; Chen, Y. The effect of PEGylation of mesoporous silica nanoparticles on nonspecific binding of serum proteins and cellular responses. Biomaterials 2010, 31, 1085-1092.

(32) Walkey, C. D.; Olsen, J. B.; Guo, H.; Emili, A.; Chan, W. C. W. Nanoparticle Size and Surface Chemistry Determine Serum Protein Adsorption and Macrophage Uptake. J. Am. Chem. Soc. 2012, 134, 2139-2147.

(33) Bertrand, N.; Grenier, P.; Mahmoudi, M.; Lima, E. M.; Appel, E. A.; Dormont, F.; Lim, J.-M.; Karnik, R.; Langer, R.; Farokhzad, O. C. Mechanistic understanding of in vivo protein corona formation on polymeric nanoparticles and impact on pharmacokinetics. Nat. Commun. 2017, 8, 777. 